\title{
Review Article \\ Epigenetic Control of Autophagy by MicroRNAs in Ovarian Cancer
}

\author{
Rossella Titone, ${ }^{1}$ Federica Morani, ${ }^{1}$ Carlo Follo, ${ }^{1}$ Chiara Vidoni, ${ }^{1}$ \\ Delia Mezzanzanica, ${ }^{2}$ and Ciro Isidoro ${ }^{1}$ \\ ${ }^{1}$ Laboratory of Molecular Pathology, Department of Health Sciences, Centro di Biotecnologie per la Ricerca \\ Medica Applicata, Università del Piemonte Orientale, Via P. Solaroli 17, 28100 Novara, Italy \\ ${ }^{2}$ Unit of Molecular Therapies, Department of Experimental Oncology and Molecular Medicine, Fondazione IRCCS Istituto \\ Nazionale dei Tumori, 20133 Milan, Italy
}

Correspondence should be addressed to Ciro Isidoro; ciro.isidoro@med.unipmn.it

Received 27 January 2014; Accepted 14 April 2014; Published 30 April 2014

Academic Editor: Yong-Sang Song

Copyright (C) 2014 Rossella Titone et al. This is an open access article distributed under the Creative Commons Attribution License, which permits unrestricted use, distribution, and reproduction in any medium, provided the original work is properly cited.

\begin{abstract}
Autophagy is a lysosomal-driven catabolic process that contributes to the preservation of cell homeostasis through the regular elimination of cellular damaged, aged, and redundant molecules and organelles. Autophagy plays dual opposite roles in cancer: on one hand it prevents carcinogenesis; on the other hand it confers an advantage to cancer cells to survive under prohibitive conditions. Autophagy has been implicated in ovarian cancer aggressiveness and in ovarian cancer cell chemoresistance and dormancy. Small noncoding microRNAs (miRNAs) regulate gene expression at posttranscriptional level, thus playing an important role in many aspects of cell pathophysiology, including cancerogenesis and cancer progression. Certain miRNAs have recently emerged as important epigenetic modulators of autophagy in cancer cells. The mRNA of several autophagy-related genes contains, in fact, the target sequence for miRNAs belonging to different families, with either oncosuppressive or oncogenic activities. MiRNA profiling studies have identified some miRNAs aberrantly expressed in ovarian cancer tissues that can impact autophagy. In addition, plasma and stroma cell-derived miRNAs in tumour-bearing patients can regulate the expression of relevant autophagy genes in cancer cells. The present review focuses on the potential implications of miRNAs regulating autophagy in ovarian cancer pathogenesis and progression.
\end{abstract}

\section{Introduction}

The research fields of autophagy and microRNAs (miRNAs) are relatively new (less than 20 years from their definition and discovery) and our knowledge of these fields is in tremendous expansion; on the other hand, the ovary cancer remains a deadly disease since no significant improvement in overall survival was achieved in the last three decades [1]. Here we focus on the involvement of macroautophagy in the pathogenesis of cancer and on the molecular significance of miRNAs that potentially regulate this process. Targeting of the autophagy pathway is being under evaluation as a new anticancer therapeutic option $[2,3]$. Therefore, unravelling the clinical implications of autophagy-miRNA interaction in ovary cancer might hopefully open the way to new diagnostic and molecular therapeutic approaches for this highly malignant disease.

\section{MicroRNAs and Cancer}

Over the last decade, several classes of molecules that form a complex transcriptional regulatory network are being identified and still their complete characterization is ongoing [4]. The most well-known small noncoding RNAs, discovered nearly 20 years ago, are the miRNAs, which posttranscriptionally regulate gene expression through base pairing with the $3^{\prime}$-untranslated region of target mRNAs [5]. MiRNA-mediated repression of gene expression occurs 
through complex mechanisms not fully understood, including translational inhibition and mRNA degradation [6]. MiRNAs, as master regulators of gene expression, are among the major players in development, cell biology, and disease onset; in fact, it has been estimated that miRNAs can regulate the expression of more than half of protein-coding sequences in mammalian genomes. Accumulating evidence shows that miRNA expression is dysregulated in many types of cancer and that they can act either as oncogenes or tumour suppressors, depending on the cellular context and the expression of the miRNA targets in the particular tissue (reviewed in [7]). The effects of miRNA deregulation in cancer progression, diagnosis, and therapy have been extensively reviewed $[8,9]$.

\section{Autophagy and Cancer}

3.1. Morphological Aspects and Biochemical Regulation of Autophagy in Brief. Autophagy refers to a cellular process committed to the lysosomal degradation of self-constituents $[10,11]$. Depending on the mechanism through which the substrate is delivered into the lysosome, autophagy is classified as macroautophagy, microautophagy, and chaperonmediated autophagy [12-15]. However, macroautophagy (now simply referred to as autophagy) is the process mainly subjected to fluctuations to comply the needs for keeping cell homeostasis in response to stressful injuries. Autophagy, in fact, is the only pathway allowing the degradation of macromolecular aggregates, portion of cytoplasm, membranes, and entire organelles [16]. In this process, the autophagy substrate is sequestered within a newly formed vesicle (named autophagosome) that subsequently fuses with several endosomes and lysosomes to form autophagolysosomes (or autolysosomes) in which the autophagy substrate is fully degraded by the lysosomal acid hydrolases [17]. The substrates are selectively incorporated within the nascent autophagosomes through the intervention of proteins, such as p62/SQSTM1 (sequestosome), NBR1 (neighbour of BRCA1 gene 1 ), and Nix/BNIP3, that bridge the substrate and the membrane-bound LC3 [18-20]. LC3 (light chain 3; the mammalian orthologue of yeast atg8) derives from the posttranslational modification of MAP-LC3 (microtubuleassociated protein-LC3) and is specifically associated with autophagosomal membranes [21]. The autophagosome originates from the nucleation and expansion of a preautophagosomal structure, a double-layered omega-shaped semicircle originating from the smooth endoplasmic reticulum [22]. Eventually, this structure closes up to form the autophagosome, which entraps the cargo. While being on formation, the lipidated isoform LC3-II is inserted onto the internal and external membranes of the autophagosome. The autophagosomes then move toward the microtubular organizing center, where they meet and fuse with the lysosomes [23]. The cargo is then completely degraded, along with the internal membrane of the autophagosome, within the acidic lumen of the autophagolysosome [24]. LC3-II present on the internal membrane of the autophagosome is also degraded, so that its consumption serves as readout of the autophagy flux [21]. Finally, the monomeric substrates are then pumped out in the cytosol for recycling purposes [25].

The autophagy pathway is controlled by a variety of signalling molecules $[26,27]$. The ULK1 (Unc51-like kinase 1, the homolog of the yeast Atg1) kinase is believed to master the induction of autophagy [28]. Its function is under the control of two upstream kinases, AMPk and mTOR. Schematically, the class I PI3-k-AKT signalling pathway negatively impinges on autophagy through the activation of mTOR complex 1 (mTORC1), which inhibits the ULK1 complex, while the LKBAMPk signalling pathway positively regulates autophagy through the inactivation of $\mathrm{MTORCl}$ and the direct activation of ULK1 [29]. The activation of these pathways is influenced by intracellular and extracellular factors. The availability of nutrients (essentially, glucose and amino acids) and of growth factors activates the class I PI3k-AKT-mTORC1 pathway, thus repressing autophagy, whereas starvation strongly induces autophagy [30, 31]. On the other hand, energy depletion (i.e., shortage of ATP), oxidative stress, and DNA damage activate the LKB-AMPk pathway and therefore trigger autophagy [32-35]. The ULK1 complex signals to (also known as Vps34), which forms an active complex with Beclin-1 (also known as ATG6 or Vps30) [31]. This complex is recruited at the level of the preautophagosomal structure and locally produces PI3P (phosphatidyl -3-phosphate), the starting platform for the recruitments of membranes necessary for the biogenesis of the autophagosome [12].

3.2. The Pathophysiological Role of Autophagy in Cancer. The role of autophagy in cancer biology is not unequivocal. While basal (constitutive) autophagy prevents carcinogenesis through the constant elimination of damaged molecules and organelles that may increase the probability of oxidative stress mediated DNA mutation [36], induced autophagy can help cancer cells to face adverse situations such as the metabolic stress due to hypoxia and hyponutrition or the damaged provoked by anticancer treatments $[37,38]$. In addition, the upregulation of autophagy may switch cancer cells into a dormant state, thus posing the basis for tumour relapse [3941].

Many oncogenes and oncosuppressors regulate autophagy [42]. In general, oncogenes (e.g., AKT, BCL2) tend to repress autophagy, though for some of them (e.g., RAS) the final effect is cell context dependent [43-46]. It has been proposed that the abnormal expression of oncogenes favours the induction of prosurvival autophagy in cancer cells experiencing a metabolic stress. By contrast, oncosuppressors (e.g., PTEN, TSC1/TSC2, and DAPk) positively regulate autophagy and thus their lack reduces or abrogates the level of basal and inducible autophagy. Consistently, loss of function of the oncosuppressors Beclin-1 $[47,48]$ or PTEN $[49,50]$ predisposes to spontaneous cancers. The role of the oncosuppressor p53 in the regulation of autophagy in cancer cells appears ambiguous: while nuclear DNA-binding proficient p53 promotes the transcription of certain autophagy genes [51], p53 mutants that reside in the cytoplasm hamper autophagy $[52,53]$. 
Besides, microenvironmental factors (hypoxia, $\mathrm{pH}$, oxidative stress, nutrient availability, cytokines, hormones, and growth factors) and the physical-metabolic interaction of tumour cells with surrounding cells (inflammatory cells, fibroblasts) in the matrix greatly influence the actual level of autophagy in the cancer cells [54-56].

\section{Ovarian Cancer Genesis and Progression: The Potential Role of MicroRNAs and of Autophagy}

4.1. Involvement of Autophagy in the Pathogenesis of Ovarian Cancer. Based on the traditional view, ovarian tumours arise from subsequent metaplastic changes in the ovarian surface epithelium that lead to the development of four main histologic types: serous, endometrioid, mucinous, and clear cell (for a review see, [57]). More recently, the correlation of clinicopathological features with genetic studies has suggested a new paradigm for the pathogenesis and origin of epithelial ovarian cancer based on a dualistic model of carcinogenesis that classifies ovarian cancer in two types [58]. Type I tumours comprise low grade serous and endometrioid carcinomas, clear cells, and mucinous carcinomas which develop in a stepwise fashion from well-defined precursor lesions. They are indolent and relatively genetically stable, being characterized by a variety of somatic mutations or amplification/deletion of oncogenes or oncosuppressors including K-RAS, B-RAF, and PTEN [59, 60]. In contrast, type II tumours comprise high-grade serous and endometrioid carcinomas, malignant mixed mesodermal carcinomas, and undifferentiated carcinomas; they are rapidly growing and highly aggressive. Type II tumours are chromosomally unstable and express mutated TP53 in more than $95 \%$ of the cases and BRCA inactivation in up to $50 \%$ of high-grade serous tumours (for a review see [61]). Besides these genetic abnormalities, also epigenetic alterations in the expression of critical genes may occur during cancer progression, and these changes are reflected in the signalling pathways that govern cell proliferation, cell migration, dormancy, and chemoresistance. At least 15 oncogenes and 16 oncosuppressor genes have been found deregulated in ovarian cancers because of genetic or epigenetic alterations [62-64]. Many of these oncogenes and oncosuppressors have also been involved in the regulation of autophagy [65]. Indeed, there is experimental evidence linking autophagy to ovarian cancer genesis. For instance, poorly differentiated and highly malignant ovarian cancer cells were shown to express very low level of the autophagosomal marker LC3, compared to benign hyperplastic tissues and borderline ovarian tumours [66]. The expression of the oncosuppressor $B E C N$ 1, which activates PI3k III-dependent autophagy (see above), was found downregulated in ovarian cancers, compared to benign lesions [66]. Also DRAM (damage-regulated autophagy regulator) 2, a p53-transcribed gene that positively regulates autophagy [67], was found to be expressed at very low level in aggressive ovarian tumours [68]. As many as 60 to $80 \%$ of both sporadic and familial ovarian cancers have been shown to bear mutations and deletions of the oncosuppressor
TP53 gene $[64,69,70]$. Deletion of TP53 could favour high level of basal autophagy [71], whereas DNA-binding deficient p53 mutants, which are found in human ovarian carcinomas [72], are unable to sequester BCL-2 or BCL-XL and indirectly could inhibit autophagy [53]. On the other hand, the hyperactivation of $\mathrm{mTOR}$, which results in suppression of basal autophagy, was associated with a poor prognosis in ovarian carcinoma patients [73]. Taken together, it seems that ovarian carcinogenesis associates with insufficient autophagy. Another interesting gene linking autophagy and ovarian cancer is the aplasia ras-homolog member 1 ( $A R H 1$; also known as DIRAS3), which codes for a ras-homolog $26 \mathrm{kDa}$ GTPase. The expression of $A R H I$ correlates with prolonged progression-free survival and has been found downregulated in more than $60 \%$ of ovarian cancers $[74,75]$. ARH1 is an imprinted oncosuppressor gene (one allele is inherited in a hypermethylated form), and therefore one single event (deletion, mutation, or epigenetic silencing) affecting the functioning allele is sufficient to cause the loss of function $[76,77]$. ARH1 protein has recently been shown to modulate autophagy and dormancy in ovarian cancer cells [40]. It was shown that reactivation of $A R H I$ by stromal factors could rescue dormant ovarian cancer cells through modulation of autophagy [40].

4.2. Modulation of Autophagy by MicroRNAs. Considering the implications of both miRNAs and autophagy in cancerrelated processes and given the lack of current evidence linking these two rapidly growing fields of research, we prompted to review miRNAs regulating autophagy.

Recently, Jegga et al. used a system biology-based approach to define the complex regulatory and functional networks of genes controlling the autophagy-lysosomal pathway and found miR-130, miR-98, miR-124, miR-204, and miR-142 as putative posttranscriptional regulators of this pathway at various levels [78].

In principle, autophagy could be regulated by miRNAs targeting the mRNA of key molecules that indirectly induce or suppress autophagy, as, for instances, miR-504 that negatively regulates p53 [79] or miR-20b that negatively regulates the expression of HIF-1 $\alpha$ [80] or any miRNA implicated in the regulation of the PI3k-(PTEN)-AKT-mTOR pathway as is, for instance, the case of miRNAs targeting PTEN [81]. More recently, miRNAs specifically targeting the mRNA of autophagy proteins are being identified [82]. For instance, members of the miR30 family can target Beclin-1, ATG2, ATG5, and ATG12 [83, 84]; miR-130a targets ATG2B [85]; mi-R181a-1 targets ATG5 [86, 87]; miR-290-295 targets ATG7 and ULK1 [88]; miRNA-17 and miR-119a-5p target ATG7 $[89,90]$; miR376b targets ATG4 and BECLIN-1 [91]; miR-630 targets ATG12 [86]; and miR-519 targets Beclin-1, ATG10, and ATG16L1 [86].

Here, we will focus on those miRNAs that are either upor downexpressed in ovarian cancers and that potentially regulate autophagy.

4.3. MicroRNAs Aberrantly Expressed in Ovarian Cancer. Comparative miRNAs expression profiling of ovarian cancer 
TABLE 1: (a) Autophagy-related genes and their function identified as targets of the microRNA involved in ovarian cancer development and progression (miRanda release, August 2010; TargetScan release 6.2.). (b) Genes coding for autophagy-regulating molecules identified as targets of the microRNA involved in ovarian cancer development and progression (miRanda release, August 2010; TargetScan release 6.2.).

(a)

\begin{tabular}{|c|c|c|c|c|}
\hline $\begin{array}{l}\text { miRNAs (involved in ovarian } \\
\text { cancer progression) }\end{array}$ & $\begin{array}{l}\text { Predicted autophagy } \\
\text { Target Genes }\end{array}$ & Function & \multicolumn{2}{|c|}{$\begin{array}{l}\text { Target prediction } \\
\text { miRanda TargetScan }\end{array}$} \\
\hline $\begin{array}{l}\text { hsa-miR-141 } \\
\text { hsa-miR 200a }\end{array}$ & ATG7 & $\begin{array}{l}\text { A ubiquitin-activating (E1) enzyme homolog that } \\
\text { activates both ATG8/LC3 and ATG12 }\end{array}$ & Yes & Yes \\
\hline \multirow{3}{*}{ hsa-miR-199a -5p } & ATG14L & A component of the class III PtdIns 3-kinase complex & No & Yes \\
\hline & $A T G 4 D$ & Processing of MAP1-LC3 & Yes & Yes \\
\hline & $B E C N 1$ & $\begin{array}{l}\text { BCL-2 interacting myosin/moesin-like coiled-coil } \\
\text { protein 1, part of the class III PtdIns 3-kinase complex } \\
\text { (activating macroautophagy) }\end{array}$ & Yes & Yes \\
\hline hsa-miR-214 & ATG14L & A component of the class III PtdIns 3-kinase complex & No & Yes \\
\hline \multirow{3}{*}{ hsa-miR-182 } & ATG7 & $\begin{array}{l}\text { A ubiquitin-activating (E1) enzyme homolog that } \\
\text { activates both ATG8/LC3 and ATG12 }\end{array}$ & Yes & Yes \\
\hline & ATG16L1 & $\begin{array}{l}\text { A component of the ATG12-ATG5-ATG16 complex for } \\
\text { the formation of autophagosome }\end{array}$ & Yes & Yes \\
\hline & $M A P 1 L C 3 B$ & $\begin{array}{l}\text { Microtubule-associated protein } 1 \text { light chain } 3 \text {, } \\
\text { precursor of LC3-II inserted in autophagosomal } \\
\text { membranes }\end{array}$ & Yes & Yes \\
\hline hsa-miR-140-5p & ATG14L & A component of the class III PtdIns 3-kinase complex & No & Yes \\
\hline hsa-miR-125b & $U V R A G$ & $\begin{array}{l}\text { Interacting with Beclin-1 and Bif-1 (activation and } \\
\text { stimulation of macroautophagy) }\end{array}$ & Yes & Yes \\
\hline \multirow{2}{*}{ hsa-miR-34a } & ATG4B & Processing of MAP1-LC3 & Yes & Yes \\
\hline & ATG9A & $\begin{array}{l}\text { A transmembrane protein involved in lipid transport } \\
\text { for phagophore expansion }\end{array}$ & Yes & Yes \\
\hline \multirow{3}{*}{ hsa-let-7a } & $A T G 4 B$ & Processing of MAP1-LC3 & Yes & Yes \\
\hline & ATG9A & $\begin{array}{l}\text { A transmembrane protein involved in lipid transport } \\
\text { for phagophore expansion }\end{array}$ & Yes & Yes \\
\hline & $A T G 16 L 1$ & $\begin{array}{l}\text { A component of the ATG12-ATG5-ATG16 complex for } \\
\text { the formation of autophagosome }\end{array}$ & Yes & Yes \\
\hline \multirow{3}{*}{$\begin{array}{l}\text { hsa-miR-15a } \\
\text { hsa-miR-15b }\end{array}$} & ATG13 & $\begin{array}{l}\text { A component of the ULK1 complex needed for ULK1 } \\
\text { kinase activity }\end{array}$ & No & Yes \\
\hline & ATG9A & $\begin{array}{l}\text { A transmembrane protein involved in lipid transport } \\
\text { for phagophore expansion }\end{array}$ & Yes & Yes \\
\hline & ATG14L & A component of the class III PtdIns 3-kinase complex & No & Yes \\
\hline hsa-miR-210 & ATG7 & $\begin{array}{l}\text { A ubiquitin-activating (E1) enzyme homolog that } \\
\text { activates both ATG8/LC3 and ATG12 }\end{array}$ & Yes & Yes \\
\hline hsa-miR-449b & $A T G 4 B$ & Processing of MAP1-LC3 & Yes & Yes \\
\hline
\end{tabular}

(b)

\begin{tabular}{lclcl}
\hline $\begin{array}{l}\text { miRNAs (involved in } \\
\text { ovarian cancer progression) }\end{array}$ & $\begin{array}{c}\text { Predicted autophagy } \\
\text { Target genes }\end{array}$ & Function & $\begin{array}{l}\text { Target prediction } \\
\text { miRanda TargetScan }\end{array}$ \\
\hline $\begin{array}{l}\text { hsa-miR-141 } \\
\text { hsa-miR 200a }\end{array}$ & PTEN & $\begin{array}{l}\text { Protein/lipid phosphatase that reduces the level of PIP3, } \\
\text { thus limiting the activation of AKT } \\
\text { Tuberose Sclerosis Complex component that negatively } \\
\text { regulates mTOR }\end{array}$ & Yes & Yes \\
\hline $\begin{array}{l}\text { hsa-miR 200b } \\
\text { hsa-miR 200c }\end{array}$ & PTEN & $\begin{array}{l}\text { Protein/lipid phosphatase that reduces the level of PIP3, } \\
\text { thus limiting the activation of AKT }\end{array}$ & Yes & Yes \\
\hline TSC1 & $\begin{array}{l}\text { Tuberose Sclerosis Complex component that negatively } \\
\text { regulates mTOR } \\
\text { Interactor of Beclin-1 (represses autophagy) and of BAX } \\
\text { (represses apoptosis) }\end{array}$ & Yes & Yes & Yes \\
\hline
\end{tabular}


(b) Continued.

\begin{tabular}{|c|c|c|c|c|}
\hline $\begin{array}{l}\text { miRNAs (involved in } \\
\text { ovarian cancer progression) }\end{array}$ & $\begin{array}{l}\text { Predicted autophagy } \\
\text { Target genes }\end{array}$ & Function & $\begin{array}{l}\text { Target } 1 \\
\text { miRanda }\end{array}$ & $\begin{array}{l}\text { prediction } \\
\text { TargetScan }\end{array}$ \\
\hline \multirow{2}{*}{ hsa-miR-125b } & $U V R A G$ & $\begin{array}{l}\text { Interacting with Beclin-1 and Bif-1 (activation and } \\
\text { stimulation macroautophagy) }\end{array}$ & Yes & Yes \\
\hline & $B C L 2$ & $\begin{array}{l}\text { Interactor of Beclin-1 (represses autophagy) and of BAX } \\
\text { (represses apoptosis) }\end{array}$ & Yes & Yes \\
\hline \multirow[t]{2}{*}{ hsa-miR-101 } & MTOR & $\begin{array}{l}\text { Mammalian target of rapamycin (kinase) component of } \\
\text { MTORC1 (that inhibits autophagy) and of MTORC2 } \\
\text { (that phosphorylates Akt) }\end{array}$ & No & Yes \\
\hline & $R A B 5 A$ & $\begin{array}{l}\text { Endocytic vesicle associated ras-homolog GTPase } \\
\text { (involved in autophagosome formation) }\end{array}$ & Yes & Yes \\
\hline hsa-miR-31 & $R A B 1 B$ & $\begin{array}{l}\text { Endocytic vesicle associated ras-homolog GTPase } \\
\text { (involved in autophagosome formation) }\end{array}$ & Yes & Yes \\
\hline hsa-miR-34a & $B C L 2$ & $\begin{array}{l}\text { Interactor of Beclin-1 (represses autophagy) and of BAX } \\
\text { (represses apoptosis) }\end{array}$ & Yes & Yes \\
\hline has-let-7a & TSC1 & $\begin{array}{l}\text { Tuberose Sclerosis Complex component that negatively } \\
\text { regulates mTOR }\end{array}$ & Yes & Yes \\
\hline \multirow{3}{*}{$\begin{array}{l}\text { hsa-miR-15a } \\
\text { hsa-miR-15b }\end{array}$} & $B C L 2$ & $\begin{array}{l}\text { Interactor of BECLIN } 1 \text { (represses autophagy) and of } \\
\text { BAX (represses apoptosis) }\end{array}$ & Yes & Yes \\
\hline & TSC1 & $\begin{array}{l}\text { Tuberose Sclerosis Complex component that negatively } \\
\text { regulates mTOR }\end{array}$ & Yes & Yes \\
\hline & $F K B P 1 A$ & $\begin{array}{l}\text { An immunophilin that forms a complex with } \\
\text { rapamycin and inhibits mTOR activity }\end{array}$ & Yes & Yes \\
\hline \multirow[b]{2}{*}{ hsa-miR-155 } & PDK1 & Kinase that phosphorylates AKT in Thr308 & Yes & Yes \\
\hline & RPTOR & $\begin{array}{l}\text { Regulatory associated protein of mTOR (component of } \\
\text { MTORC1) }\end{array}$ & No & Yes \\
\hline $\begin{array}{l}\text { hsa-miR-99a } \\
\text { hsa-miR-100 }\end{array}$ & MTOR & $\begin{array}{l}\text { Mammalian target of rapamycin (kinase) component of } \\
\text { MTORC1 (that inhibits autophagy) and of MTORC2 } \\
\text { (that phosphorylates Akt) }\end{array}$ & No & Yes \\
\hline hsa-miR-449b & $B C L 2$ & $\begin{array}{l}\text { Interactor of Beclin-1 (represses autophagy) and of BAX } \\
\text { (represses apoptosis) }\end{array}$ & Yes & Yes \\
\hline
\end{tabular}

and normal ovary epithelium specimens has been performed in several laboratories and the readers can refer to some excellent comprehensive reviews $[92,93]$. The laboratory of Carlo Croce first reported on the differential expression of some miRNAs between normal and cancer ovary epithelial tissues, showing an upregulation of miR-200a/b/c, miR141, miR-21, miR-203, and miR-205 and a downregulation of miR199a, miR-140, miR-145, miR-222, and miR-125b1 [94]. In another study, miR-21 was found as the most upregulated and miR-125b as the most downregulated miRNA in ovary cancer versus normal ovary epithelium tissues [95]. However, a clear consensus on the diagnostic and prognostic value of a miRNA signature has not been reached yet. One study reported the complete downregulation of 44 miRNAs (including the oncosuppressive miR-15a, miR-34a, and miR-34b) and the upregulation of miR-182 in late-stage ovary cancers [96]. Another group found miR-199a, miR-214, and miR-200a as the ones most upregulated and miR-100 as the most downregulated miRNA in high-grade and late-stage ovary cancers [97]. Also miR-200a, miR-34a, and miR-449b were found downregulated in late-stage ovary cancers [98]. Latestage ovary cancers are associated with the acquisition of chemotherapy resistance and metastasis formation, with the latter resulting from the phenotypic transformation known as epithelial-to-mesenchymal transition (EMT). A miRNA signature of the mesenchymal-like phenotype of epithelial ovary cancer was shown to include miR-141, miR-200, miR29c, miR-101, miR-506, and miR-128 [99]. Further, the response to chemotherapeutics (e.g., Platinum) was found to be associated with a particular miRNA signature that includes let-7i [100], hsa-miR-27a, hsa-miR-23a, and miR-378 $[98,101]$.

In searching for the molecular pathways responsible for the metabolic and phenotypic alterations associated with a certain miRNA signature, it must be taken into account that one single miRNA can target the mRNA of multiple genes and that one single mRNA can have multiple target sequences for different miRNAs. Recently, another level of complexity in the global regulation of gene expression by miRNAs has emerged. It was in fact shown that the overexpression of certain miRNAs could indirectly regulate the level of other miRNAs in ovarian cancer cells [102].

4.4. Regulation of Autophagy by MicroRNA Aberrantly Expressed in Ovarian Cancer. As stated above, the modulation of autophagy by environmental stressful conditions (nutrient depletion, hypoxia, oxidative stress, and 
TABLE 2: Genes coding for proteins involved in the autophagy pathway identified as targets of microRNA involved in the cytotoxic response to cis-Platinum in ovarian cancer (miRanda release, August 2010; TargetScan release 6.2.).

\begin{tabular}{|c|c|c|c|c|}
\hline \multirow{2}{*}{$\begin{array}{l}\text { miRNAs } \\
\text { (involved in cis-Pt response) }\end{array}$} & \multirow{2}{*}{$\begin{array}{l}\text { Predicted gene(s) } \\
\text { involved in autophagy }\end{array}$} & \multirow{2}{*}{ Function } & \multicolumn{2}{|c|}{ Target prediction } \\
\hline & & & miRanda & TargetScan \\
\hline \multirow[b]{2}{*}{ hsa-miR-27a } & $P D K 1$ & Kinase for the phosphorylation of AKT in Thr308 & Yes & Yes \\
\hline & TSC1 & $\begin{array}{l}\text { Tuberose Sclerosis Complex component that } \\
\text { negatively regulates mTOR }\end{array}$ & Yes & Yes \\
\hline \multirow{6}{*}{ hsa-miR-23a } & UVRAG & $\begin{array}{l}\text { Interacts with Beclin-1 and Bif-1 (activation and } \\
\text { stimulation macroautophagy) }\end{array}$ & Yes & Yes \\
\hline & ATG12 & $\begin{array}{l}\text { A ubiquitin-like protein that modifies } \\
\text { (autophagosome expansion) }\end{array}$ & Yes & Yes \\
\hline & $B C L 2$ & $\begin{array}{l}\text { Interactor of Beclin-1 (represses autophagy) and of } \\
\text { Bax (represses apoptosis) }\end{array}$ & Yes & Yes \\
\hline & PTEN & $\begin{array}{l}\text { Protein/lipid phosphatase that reduces the level of } \\
\text { PIP3, thus limiting the activation of AKT }\end{array}$ & Yes & Yes \\
\hline & TSC1 & $\begin{array}{l}\text { Tuberose Sclerosis Complex component that } \\
\text { negatively regulates mTOR }\end{array}$ & Yes & Yes \\
\hline & RAPTOR & $\begin{array}{l}\text { Regulatory associated protein of mTOR (component } \\
\text { of MTORC1) }\end{array}$ & No & Yes \\
\hline hsa-miR-378 & - & & & \\
\hline \multirow{3}{*}{ hsa-let-7i } & $A T G 4 B$ & Processing of MAP1-LC3 & Yes & Yes \\
\hline & ATG16L1 & $\begin{array}{l}\text { A component of the ATG12-ATG5-ATG16 complex } \\
\text { for the formation of autophagosome }\end{array}$ & Yes & Yes \\
\hline & TSC1 & $\begin{array}{l}\text { Tuberose Sclerosis Complex component that } \\
\text { negatively regulates mTOR }\end{array}$ & Yes & Yes \\
\hline
\end{tabular}

chemotherapeutic drugs) and/or by genetic and epigenetic hints may confer resistance to the chemotherapeutic treatments in cancer cells and may also favour the EMT and metastasization of cancer cells [103]. MiRNAs could contribute to the modulation of autophagy in these situations. For instance, the treatment with cisplatin could induce chemoresistance-promoting autophagy through the downregulation of certain miRNAs targeting ATG proteins or the pathways that control autophagy. As an example, miR214 was shown to confer cisplatin resistance in ovarian cancer cells by targeting PTEN [97], and PTEN is known to positively regulate autophagy [104]. PTEN expression is posttranscriptionally regulated by a set of miRNAs $[81,97$, 105]. In ovarian cancers, overexpression of miR-21 correlated with late stage and metastasis and significantly decreased the expression of PTEN [106].

We have made an "in silico" search of the ATG genes that are potential target candidates of the most relevant miRNAs found aberrantly expressed in ovary cancers. In Table 1 we report the results obtained using two algorithms for the prediction of microRNA gene targets, namely, the "TargetScanHuman" [107] and the miRanda [108] software. We have considered three different sets of miRNAs: in Tables 1(a) and 1(b) are reported the miRNAs that were found aberrantly expressed (either up- or downregulated with respect to the normal ovary epithelium) in ovarian cancers and that are possibly involved in ovarian tumorigenesis and progression; in Table 2 are reported the miRNAs that apparently play a role in chemoresistance; in Table 3 are reported the miRNAs that were found involved in the epithelial-to-mesenchymal transition of the phenotype. For clarity, in Table 1 we have separately described the ATG genes coding for ATG proteins (a) and the genes coding for signalling molecules that directly or indirectly control the induction and progression of autophagy. (b) In the tables, we also describe the function of the proteins coded by the genes predictably targeted by the miRNAs. In general, the two algorithms agreed in the identification of ATG target genes for most of the miRNAs of interest. The main discordances between miRanda and TargetScan were relative to the recognition of ATG14L as target of miR-21, miR-214, miR-140, miR-15a, and miR15b, and of ATG13 as a target of miR-15a and miR15b.

For some of these miRNAs the ATG gene target has been validated in tumours other than ovarian cancer. Although these data should be considered with caution due to the possible context and tissue specificity of miRNA regulation, we can assume that some available information can be applied also to ovarian cancer. For instance miR-101, reported to act as inhibitor of autophagy in breast cancer by targeting STMN1, RAB5A, and ATG4D mRNAs [109], has been found downregulated also in ovarian cancer compared to normal tissue, and its reexpression exerted tumour-suppressive effects in ovarian carcinogenesis [110]. Of note, stathmin overexpression showed a significant association with poor prognosis in ovarian cancer patients [111]. In keeping with the potential of miR-101 to regulate autophagy and ovarian cancer progression, it is to be mentioned that its target RAB5A was shown to be upregulated and to promote cell 
TABLE 3: Genes coding for proteins involved in the autophagy pathway identified as targets of the microRNA involved in the epithelial-tomesenchymal transition process in ovarian cancer (miRanda release, August 2010; TargetScan release 6.2.).

\begin{tabular}{|c|c|c|c|c|}
\hline \multirow{2}{*}{$\begin{array}{l}\text { miRNAs } \\
\text { (involved in EMT) }\end{array}$} & \multirow{2}{*}{$\begin{array}{l}\text { Predicted gene(s) } \\
\text { involved in autophagy }\end{array}$} & \multirow{2}{*}{ Function } & \multicolumn{2}{|c|}{ Target prediction } \\
\hline & & & miRanda & TargetScan \\
\hline \multirow{3}{*}{$\begin{array}{l}\text { hsa-miR-141 } \\
\text { hsa-miR 200a }\end{array}$} & ATG7 & $\begin{array}{l}\text { A ubiquitin-activating (E1) enzyme homolog that } \\
\text { activates both ATG8/LC3 and ATG12 }\end{array}$ & Yes & Yes \\
\hline & PTEN & $\begin{array}{l}\text { Protein/lipid phosphatase that reduces the level of PIP3, } \\
\text { thus limiting the activation of AKT }\end{array}$ & Yes & Yes \\
\hline & TSC1 & $\begin{array}{l}\text { Tuberose Sclerosis Complex component that negatively } \\
\text { regulates mTOR }\end{array}$ & Yes & Yes \\
\hline \multirow[b]{2}{*}{ hsa-miR 29c } & ATG14L & A component of the class III PtdIns 3-kinase complex & No & Yes \\
\hline & PTEN & $\begin{array}{l}\text { Protein/lipid phosphatase that reduces the level of PIP3, } \\
\text { thus limiting the activation of AKT }\end{array}$ & Yes & Yes \\
\hline \multirow[t]{2}{*}{ hsa-miR-101 } & MTOR & $\begin{array}{l}\text { Mammalian target of rapamycin (kinase) component of } \\
\text { MTORC1 (that inhibits autophagy) and of MTORC2 } \\
\text { (that phosphorylates Akt) }\end{array}$ & No & Yes \\
\hline & $R A B 5 A$ & $\begin{array}{l}\text { Endocytic vesicle associated ras-homolog GTPase } \\
\text { (involved in autophagosome formation) }\end{array}$ & Yes & Yes \\
\hline hsa-miR-506 & - & & & \\
\hline \multirow{2}{*}{ hsa-miR-128 } & $P D K 1$ & Kinase that phosphorylates AKT in Thr308 & Yes & Yes \\
\hline & TSC1 & $\begin{array}{l}\text { Tuberose Sclerosis Complex component that negatively } \\
\text { regulates mTOR }\end{array}$ & Yes & Yes \\
\hline
\end{tabular}

proliferation in ovarian cancer [112]. Also, miR-30a, which negatively regulates the expression of Beclin-1 in ovarian cancer cells [113], was found deregulated in stage I ovarian cancer patients together with other miRNAs; in particular, it was downregulated in samples from relapsing patients [114, 115]. This result is in line with possible involvement of miR30a in autophagy-dependent chemoresistance in ovarian cancers.

\section{Conclusion: Clinical Implications and Future Perspectives}

Modulation of autophagy has a great impact on the carcinogenesis process. In fact, depending on whether it is considered at the precancerous or at the advanced stage, upor downregulation of autophagy may elicit either tumourpromoting or tumour-suppressive effects $[116,117]$. The actual level of ongoing autophagy in the tumour cells is dictated by genetic mutations but also influenced by the epigenetic regulation of gene expression $[65,103]$. In the context of the intricate involvement of autophagy in cancer progression, emerging data point to the role of miRNAs as regulators of autophagy gene expression. The immediate and acute modulation of protein expression mediated by miRNAs plays a fundamental role in the adaptive response of the cell metabolism to environmental stresses such as nutrient shortage, hypoxia, and genotoxic stress. Autophagy is one of the main stress response pathways. Therefore, the modulation of ATG proteins and/or of signalling molecules that regulate autophagy by miRNAs finally impacts the capability of the cell to overcome the stress. This aspect is of particular relevance when considering the cytotoxic response of cancer cells to a chemotherapeutic drug. Chemosensitivity could be rescued by manipulating the level of miRNAs targeting autophagy. In fact, certain miRNAs can target both the autophagy and the apoptosis pathways and therefore can influence the cross-talk between these two processes and determine whether the cancer cell will resist or succumb to the toxic drug. For instance, miR-199a-5p was shown to increase chemoresistance by simultaneously promoting autophagy and suppressing apoptosis. By downregulating Beclin-1 expression, miR-30a and miR-376b downregulate not only autophagy but also apoptosis since the level of free antiapoptotic BCL-2 protein in the cell will increase. Thus, miRNAs can act as molecular switches to turn on or off either or both of the autophagy and apoptosis processes. These findings provide the rationale for designing novel therapeutic approaches combining the conventional anticancer drugs with miRNAs targeting the autophagy process.

Autophagy is clearly deregulated in ovarian cancer (reviewed in [65]), and here we have highlighted the possibility that the miRNAs aberrantly expressed in ovarian cancer could be involved in such deregulation.

The miRNA landscape of ovarian cancer is in rapid progress [118] and advance in detection and functional evaluation of miRNAs is expected to strongly contribute to unravelling the network of apoptosis and autophagy regulation in this complex disease. In the near future, studies ongoing in our and other laboratories will likely identify the miRNA signatures associated with autophagy in ovarian cancer, thus posing the basis for the possible harnessing of these miRNAs as therapeutic targets, as well as possible diagnostic-prognostic tools. 


\section{Conflict of Interests}

The authors declare that the present study was performed in the absence of any commercial or financial relationships that could be construed as a potential conflict of interests.

\section{Acknowledgments}

The authors fully acknowledge the funding support from Comoli, Ferrari \& Co. SpA (Novara, Italy), from Consorzio Interuniversitario in Biotecnologie (Trieste, Italy), and from Associazione per la Ricerca Medica Ippocrate-Rhazi (Novara, Italy). R. Titone is presently recipient of a "Lagrange" Ph.D. fellowship granted by Cassa di Risparmio di Torino (Italy). The authors are grateful to Dr. Silvana Canevari (Istituto Nazionale Tumori di Milano, Italy) for critical reading of the paper and to Dr. Paola Orsini (Istituto Nazionale Tumori di Milano, Italy) for assisting in miRNA target prediction.

\section{References}

[1] S. Vaughan, J. I. Coward, R. C. Bast Jr. et al., "Rethinking ovarian cancer: recommendations for improving outcomes," Nature Reviews Cancer, vol. 11, no. 10, pp. 719-725, 2011.

[2] M. A. Steeves, F. C. Dorsey, and J. L. Cleveland, "Targeting the autophagy pathway for cancer chemoprevention," Current Opinion in Cell Biology, vol. 22, no. 2, pp. 218-225, 2010.

[3] N. Chen and V. Karantza, "Autophagy as a therapeutic target in cancer," Cancer Biology and Therapy, vol. 11, no. 2, pp. 157-168, 2011.

[4] S. K. Lee and G. A. Calin, "Non-coding RNAs and cancer: new paradigms in oncology," Discovery Medicine, vol. 11, no. 58, pp. 245-254, 2011.

[5] M. A. Valencia-Sanchez, J. Liu, G. J. Hannon, and R. Parker, "Control of translation and mRNA degradation by miRNAs and siRNAs," Genes and Development, vol. 20, no. 5, pp. 515-524, 2006.

[6] W. Filipowicz, S. N. Bhattacharyya, and N. Sonenberg, "Mechanisms of post-transcriptional regulation by microRNAs: are the answers in sight?" Nature Reviews Genetics, vol. 9, no. 2, pp. 102114, 2008.

[7] R. Garzon, G. A. Calin, and C. M. Croce, "MicroRNAs in cancer," Annual Review of Medicine, vol. 60, pp. 167-179, 2009.

[8] M. A. Cortez, C. Ivan, P. Zhou, X. Wu, M. Ivan, and G. Adrian Calin, "MicroRNAs in cancer: from bench to bedside," Advances in Cancer Research, vol. 108, pp. 113-157, 2010.

[9] S. P. Nana-Sinkam and C. M. Croce, "MicroRNAs as therapeutic targets in cancer," Translational Research, vol. 157, no. 4, pp. 216225, 2011.

[10] N. Mizushima and B. Levine, "Autophagy in mammalian development and differentiation," Nature Cell Biology, vol. 12, no. 9, pp. 823-830, 2010.

[11] Z. Yang and D. J. Klionsky, "Eaten alive: a history of macroautophagy," Nature Cell Biology, vol. 12, no. 9, pp. 814-822, 2010.

[12] Z. Yang and D. J. Klionsky, "Mammalian autophagy: core molecular machinery and signaling regulation," Current Opinion in Cell Biology, vol. 22, no. 2, pp. 124-131, 2010.

[13] S. J. Orenstein and A. M. Cuervo, "Chaperone-mediated autophagy: molecular mechanisms and physiological relevance," Seminars in Cell and Developmental Biology, vol. 21, no. 7, pp. 719-726, 2010.
[14] R. Sahu, S. Kaushik, C. C. Clement et al., "Microautophagy of cytosolic proteins by late endosomes," Developmental Cell, vol. 20, no. 1, pp. 131-139, 2011.

[15] N. Mizushima and M. Komatsu, "Autophagy: renovation of cells and tissues," Cell, vol. 147, no. 4, pp. 728-741, 2011.

[16] B. Ravikumar, S. Sarkar, J. E. Davies et al., "Regulation of mammalian autophagy in physiology and pathophysiology," Physiological Reviews, vol. 90, no. 4, pp. 1383-1435, 2010.

[17] E. Itakura and N. Mizushima, "Characterization of autophagosome formation site by a hierarchical analysis of mammalian Atg proteins," Autophagy, vol. 6, no. 6, pp. 764-776, 2010.

[18] P. K. Kim, D. W. Hailey, R. T. Mullen, and J. LippincottSchwartz, "Ubiquitin signals autophagic degradation of cytosolic proteins and peroxisomes," Proceedings of the National Academy of Sciences of the United States of America, vol. 105, no. 52, pp. 20567-20574, 2008.

[19] V. Kirkin, D. G. McEwan, I. Novak, and I. Dikic, "A role for ubiquitin in selective autophagy," Molecular Cell, vol. 34, no. 3, pp. 259-269, 2009.

[20] R. A. Hanna, M. N. Quinsay, A. M. Orogo, K. Giang, S. Rikka, and Å. B. Gustafsson, "Microtubule-associated protein 1 light chain 3 (LC3) interacts with Bnip3 proteinto selectively remove endoplasmic reticulum and mitochondria via autophagy," The Journal of Biological Chemistry, vol. 287, no. 23, pp. 19094-19104, 2012.

[21] D. J. Klionsky, F. C. Abdalla, H. Abeliovich et al., "Guidelines for the use and interpretation of assays for monitoring autophagy," Autophagy, vol. 8, no. 4, pp. 445-544, 2012.

[22] E. L. Axe, S. A. Walker, M. Manifava et al., "Autophagosome formation from membrane compartments enriched in phosphatidylinositol 3-phosphate and dynamically connected to the endoplasmic reticulum," Journal of Cell Biology, vol. 182, no. 4, pp. 685-701, 2008.

[23] V. I. Korolchuk, S. Saiki, M. Lichtenberg et al., "Lysosomal positioning coordinates cellular nutrient responses," Nature Cell Biology, vol. 13, no. 4, pp. 453-462, 2011.

[24] J. Tong, X. Yan, and L. Yu, "The late stage of autophagy: cellular events and molecular regulation," Protein and Cell, vol. 1, no. 10, pp. 907-915, 2010.

[25] Y. Feng, D. He, Z. Yao, and D. J. Klionsky, "The machinery of macroautophagy," Cell Research, vol. 24, no. 1, pp. 24-41, 2014.

[26] E. Ogier-Denis, A. Couvineau, J. J. Maoret et al., "A heterotrimeric $\mathrm{G}_{\mathrm{i} 3}$-protein controls autophagic sequestration in the human colon cancer cell line HT-29," The Journal of Biological Chemistry, vol. 270, no. 1, pp. 13-16, 1995.

[27] Y. Chen and D. J. Klionsky, "The regulation of autophagyunanswered questions," Journal of Cell Science, vol. 124, no. 2, pp. 161-170, 2011.

[28] N. Mizushima, "The role of the Atg1/ULK1 complex in autophagy regulation," Current Opinion in Cell Biology, vol. 22, no. 2, pp. 132-139, 2010.

[29] S. Alers, A. S. Löffler, S. Wesselborg, and B. Stork, "Role of AMPK-mTOR-Ulk1/2 in the regulation of autophagy: cross talk, shortcuts, and feedbacks," Molecular and Cellular Biology, vol. 32, no. 1, pp. 2-11, 2012.

[30] H. X. Yuan, R. C. Russell, and K. L. Guan, "Regulation of PIK3C3/VPS34 complexes by MTOR in nutrient stress-induced autophagy," Autophagy, vol. 9, no. 12, 2013.

[31] C. He and B. Levine, "The Beclin 1 interactome," Current Opinion in Cell Biology, vol. 22, no. 2, pp. 140-149, 2010. 
[32] F. McAlpine, L. E. Williamson, S. A. Tooze, and E. Y. Chan, "Regulation of nutrient-sensitive autophagy by uncoordinated 51-like kinases 1 and 2," Autophagy, vol. 9, no. 3, pp. 361-373, 2013.

[33] A. Alexander, S.-L. Cai, J. Kim et al., "ATM signals to TSC2 in the cytoplasm to regulate mTORC1 in response to ROS," Proceedings of the National Academy of Sciences of the United States of America, vol. 107, no. 9, pp. 4153-4158, 2010.

[34] E. Janda, C. Isidoro, C. Carresi, and V. Mollace, "Defective autophagy in Parkinson's disease: role of oxidative stress," Molecular Neurobiology, vol. 46, no. 3, pp. 639-661, 2012.

[35] R. Castino, I. Fiorentino, M. Cagnin, A. Giovia, and C. Isidoro, "Chelation of lysosomal iron protects dopaminergic SH-SY5Y neuroblastoma cells from hydrogen peroxide toxicity by precluding autophagy and Akt dephosphorylation," Toxicological Sciences, vol. 123, no. 2, pp. 523-541, 2011.

[36] R. Mathew, S. Kongara, B. Beaudoin et al., "Autophagy suppresses tumor progression by limiting chromosomal instability," Genes and Development, vol. 21, pp. 1367-1381, 2007.

[37] G. L. Semenza, "American Journal of Physiology-Cell Physiology theme: hypoxia," American Journal of Physiology-Cell Physiology, vol. 300, no. 2, p. C225, 2011.

[38] R. Mathew, C. M. Karp, B. Beaudoin et al., "Autophagy suppresses tumorigenesis through elimination of p62," Cell, vol. 137, pp. 1062-1075, 2009.

[39] A. R. J. Young, M. Narita, M. Ferreira et al., "Autophagy mediates the mitotic senescence transition," Genes and Development, vol. 23, no. 7, pp. 798-803, 2009.

[40] Z. Lu, R. Z. Luo, Y. Lu et al., “The tumor suppressor gene ARHI regulates autophagy and tumor dormancy in human ovarian cancer cells," The Journal of Clinical Investigation, vol. 118, no. 12, pp. 3917-3929, 2008.

[41] C. G. Sanchez, P. Penfornis, A. Z. Oskowitz et al., "Activation of autophagy in mesenchymal stem cells provides tumor stromal support," Carcinogenesis, vol. 32, no. 7, pp. 964-972, 2011.

[42] M. C. Maiuri, E. Tasdemir, A. Criollo et al., "Control of autophagy by oncogenes and tumor suppressor genes," Cell Death and Differentiation, vol. 16, no. 1, pp. 87-93, 2009.

[43] B. H. Yoo, X. Wu, Y. Li et al., "Oncogenic ras-induced downregulation of autophagy mediator Beclin-1 is required for malignant transformation of intestinal epithelial cells," The Journal of Biological Chemistry, vol. 285, no. 8, pp. 5438-5449, 2010.

[44] M.-J. Kim, S.-J. Woo, C.-H. Yoon et al., "Involvement of autophagy in oncogenic K-Ras-induced malignant cell transformation," The Journal of Biological Chemistry, vol. 286, no. 15, pp. 12924-12932, 2011.

[45] J. Y. Guo, H.-Y. Chen, R. Mathew et al., "Activated Ras requires autophagy to maintain oxidative metabolism and tumorigenesis," Genes and Development, vol. 25, no. 5, pp. 460-470, 2011.

[46] M. Elgendy, C. Sheridan, G. Brumatti, and S. J. Martin, "Oncogenic Ras-induced expression of Noxa and Beclin-1 promotes autophagic cell death and limits clonogenic survival," Molecular Cell, vol. 42, no. 1, pp. 23-35, 2011.

[47] X. Qu, J. Yu, G. Bhagat et al., "Promotion of tumorigenesis by heterozygous disruption of the beclin 1 autophagy gene," The Journal of Clinical Investigation, vol. 112, no. 12, pp. 1809-1820, 2003.

[48] Z. Yue, S. Jin, C. Yang, A. J. Levine, and N. Heintz, "Beclin 1, an autophagy gene essential for early embryonic development, is a haploinsufficient tumor suppressor," Proceedings of the National
Academy of Sciences of the United States of America, vol. 100, no. 25, pp. 15077-15082, 2003.

[49] A. di Cristofano, B. Pesce, C. Cordon-Cardo, and P. P. Pandolfi, "Pten is essential for embryonic development and tumour suppression," Nature Genetics, vol. 19, no. 4, pp. 348-355, 1998.

[50] K. Podsypanina, L. H. Ellenson, A. Nemes et al., "Mutation of Pten/Mmacl in mice causes neoplasia in multiple organ systems," Proceedings of the National Academy of Sciences of the United States of America, vol. 96, no. 4, pp. 1563-1568, 1999.

[51] D. Crighton, S. Wilkinson, J. O'Prey et al., "DRAM, a p53induced modulator of autophagy, is critical for apoptosis," Cell, vol. 126, no. 1, pp. 121-134, 2006.

[52] E. Tasdemir, M. C. Maiuri, L. Galluzzi et al., "Regulation of autophagy by cytoplasmic p53," Nature Cell Biology, vol. 10, no. 6, pp. 676-687, 2008.

[53] E. Morselli, E. Tasdemir, M. C. Maiuri et al., "Mutant p53 protein localized in the cytoplasm inhibits autophagy," Cell Cycle, vol. 7, no. 19, pp. 3056-3061, 2008.

[54] R. Castino, N. Bellio, C. Follo, D. Murphy, and C. Isidoro, "Inhibition of Pi3k class III-dependent autophagy prevents apoptosis and necrosis by oxidative stress in dopaminergic neuroblastoma cells," Toxicological Sciences, vol. 117, no. 1, pp. 152-162, 2010.

[55] T. Xu, H. Su, S. Ganapathy, and Z.-M. Yuan, "Modulation of autophagic activity by extracellular $\mathrm{pH}$," Autophagy, vol. 7, no. 11, pp. 1316-1322, 2011.

[56] G. Mariño and G. Kroemer, "Ammonia: a diffusible factor released by proliferating cells that induces autophagy," Science Signaling, vol. 3, no. 124, article pe19, 2010.

[57] R. J. Kurman and I.-M. Shih, "The origin and pathogenesis of epithelial ovarian cancer: a proposed unifying theory," American Journal of Surgical Pathology, vol. 34, no. 3, pp. 433443, 2010.

[58] I.-M. Shih and R. J. Kurman, "Ovarian tumorigenesis- a proposed model based on morphological and molecular genetic analysis," American Journal of Pathology, vol. 164, no. 5, pp. 15111518, 2004.

[59] J. Abubaker, P. Bavi, W. Al-Haqawi et al., "PIK3CA alterations in Middle Eastern ovarian cancers," Molecular Cancer, vol. 8, article 51, 2009.

[60] T. Okuda, A. Sekizawa, Y. Purwosunu et al., "Genetics of endometrial cancers," Obstetrics and Gynecology International, vol. 2010, Article ID 984013, 8 pages, 2010.

[61] R. J. Kurman and I.-M. Shih, "Molecular pathogenesis and extraovarian origin of epithelial ovarian cancer-shifting the paradigm," Human Pathology, vol. 42, no. 7, pp. 918-931, 2011.

[62] R. C. Bast Jr., B. Hennessy, and G. B. Mills, "The biology of ovarian cancer: new opportunities for translation," Nature Reviews Cancer, vol. 9, no. 6, pp. 415-428, 2009.

[63] Cancer Genome Atlas Research Network, "Integrated genomic analyses of ovarian carcinoma," Nature, vol. 474, pp. 609-615, 2011.

[64] S. Kalamanathan, V. Bates, R. Lord, and J. A. Green, "The mutational profile of sporadic epithelial ovarian carcinoma," Anticancer Research, vol. 31, no. 8, pp. 2661-2668, 2011.

[65] C. Peracchio, O. Alabiso, G. Valente, and C. Isidoro, "Involvement of autophagy in ovarian cancer: a working hypothesis," Journal of Ovarian Research, vol. 5, no. 1, article 22, 2012.

[66] Y. Shen, D.-D. Li, L.-L. Wang, R. Deng, and X.-F. Zhu, "Decreased expression of autophagy-related proteins in malignant epithelial ovarian cancer," Autophagy, vol. 4, no. 8, pp. 1067-1068, 2008. 
[67] J.-H. Yoon, S. Her, M. Kim, I.-S. Jang, and J. Park, “The expression of damage-regulated autophagy modulator 2 (DRAM2) contributes to autophagy induction," Molecular Biology Reports, vol. 39, no. 2, pp. 1087-1093, 2012.

[68] S.-M. Park, K. Kim, E.-J. Lee et al., "Reduced expression of DRAM2/TMEM77 in tumor cells interferes with cell death," Biochemical and Biophysical Research Communications, vol. 390, no. 4, pp. 1340-1344, 2009.

[69] A. Yemelyanova, R. Vang, M. Kshirsagar et al., "Immunohistochemical staining patterns of p53 can serve as a surrogate marker for TP53 mutations in ovarian carcinoma: an immunohistochemical and nucleotide sequencing analysis," Modern Pathology, vol. 24, no. 9, pp. 1248-1253, 2011.

[70] A. A. Ahmed, D. Etemadmoghadam, J. Temple et al., "Driver mutations in TP53 are ubiquitous in high grade serous carcinoma of the ovary," Journal of Pathology, vol. 221, no. 1, pp. 4956, 2010.

[71] M. C. Maiuri, L. Galluzzi, E. Morselli, O. Kepp, S. A. Malik, and G. Kroemer, "Autophagy regulation by p53," Current Opinion in Cell Biology, vol. 22, no. 2, pp. 181-185, 2010.

[72] Y. Yaginuma and H. Westphal, "Abnormal structure and expression of the p53 gene in human ovarian carcinoma cell lines," Cancer Research, vol. 52, no. 15, pp. 4196-4199, 1992.

[73] M. Bunkholt Elstrand, H. P. Dong, E. Ødegaard et al., "Mammalian target of rapamycin is a biomarker of poor survival in metastatic serous ovarian carcinoma," Human Pathology, vol. 41, no. 6, pp. 794-804, 2010.

[74] Z. Lu, R. Z. Luo, H. Peng et al., "Transcriptional and posttranscriptional down-regulation of the imprinted tumor suppressor gene ARHI (DRAS3) in ovarian cancer," Clinical Cancer Research, vol. 12, no. 8, pp. 2404-2413, 2006.

[75] W. Feng, R. T. Marquez, Z. Lu et al., "Imprinted tumor suppressor genes ARHI and PEG3 are the most frequently downregulated in human ovarian cancers by loss of heterozygosity and promoter methylation," Cancer, vol. 112, no. 7, pp. 14891502, 2008.

[76] Y. Yu, S. Fujii, J. Yuan et al., "Epigenetic regulation of ARHI in breast and ovarian cancer cells," Annals of the New York Academy of Sciences, vol. 983, pp. 268-277, 2003.

[77] Y. Yu, R. Luo, Z. Lu et al., "Biochemistry and biology of ARHI (DIRAS3), an imprinted tumor suppressor gene whose expression is lost in ovarian and breast cancers," Methods in Enzymology, vol. 407, pp. 455-468, 2006.

[78] A. G. Jegga, L. Schneider, X. Ouyang, and J. Zhang, "Systems biology of the autophagy-lysosomal pathway," Autophagy, vol. 7, no. 5, pp. 477-489, 2011.

[79] W. Hu, C. S. Chan, R. Wu et al., "Negative regulation of tumor suppressor 533 by microRNA miR-504," Molecular Cell, vol. 38, no. 5, pp. 689-699, 2010.

[80] Z. Lei, B. Li, Z. Yang et al., "Regulation of HIF-1 $\alpha$ and VEGF by miR-20b tunes tumor cells to adapt to the alteration of oxygen concentration," PLoS ONE, vol. 4, no. 10, Article ID e7629, 2009.

[81] L. He, "Posttranscriptional regulation of PTEN dosage by noncoding RNAs," Science Signaling, vol. 3, no. 146, article pe39, 2010.

[82] H. Zhai, A. Fesler, and J. Ju, "MicroRNA: a third dimension in autophagy," Cell Cycle, vol. 12, no. 2, pp. 246-250, 2013.

[83] H. Zhu, H. Wu, X. Liu et al., "Regulation of autophagy by a beclin 1-targeted microRNA, miR-30a, in cancer cells," Autophagy, vol. 5, no. 6, pp. 816-823, 2009.
[84] X. Yang, X. Zhong, J. L. Tanyi et al., "mir-30d regulates multiple genes in the autophagy pathway and impairs autophagy process in human cancer cells," Biochemical and Biophysical Research Communications, vol. 431, pp. 617-622, 2013.

[85] V. Kovaleva, R. Mora, Y. J. Park et al., "miRNA-130a targets ATG2B and DICER1 to inhibit autophagy and trigger killing of chronic lymphocytic leukemia cells," Cancer Research, vol. 72, no. 7, pp. 1763-1772, 2012.

[86] Y. Huang, R. Guerrero-Preston, and E. A. Ratovitski, "Phospho$\Delta \mathrm{Np} 63 \alpha$-dependent regulation of autophagic signaling through transcription and micro-RNA modulation," Cell Cycle, vol. 11, no. 6, pp. 1247-1259, 2012.

[87] K. A. Tekirdag, G. Korkmaz, D. G. Ozturk, R. Agami, and D. Gozuacik, "MIR181A regulates starvation- and rapamycininduced autophagy through targeting of ATG5," Autophagy, vol. 9, no. 3, pp. 374-385, 2013.

[88] Y. Chen, R. Liersch, and M. Detmar, "The miR-290-295 cluster suppresses autophagic cell death of melanoma cells," Scientific Reports, vol. 2, article 808, 2012.

[89] S. Comincini, G. Allavena, S. Palumbo et al., "microRNA-17 regulates the expression of ATG7 and modulates the autophagy process, improving the sensitivity to temozolomide and lowdose ionizing radiation treatments in human glioblastoma cells," Cancer Biology \& Therapy, vol. 14, no. 7, pp. 574-586, 2013.

[90] N. Xu, J. Zhang, C. Shen et al., "Cisplatin-induced downregulation of miR-199a-5p increases drug resistance by activating autophagy in HCC cell," Biochemical and Biophysical Research Communications, vol. 423, no. 4, pp. 826-831, 2012.

[91] G. Korkmaz, C. le Sage, K. A. Tekirdag, R. Agami, and D. Gozuacik, "miR-376b controls starvation and mTOR inhibition-related autophagy by targeting ATG4C and BECN1," Autophagy, vol. 8, no. 2, pp. 165-176, 2012.

[92] G. di Leva and C. M. Croce, "The role of microRNAs in the tumorigenesis of ovarian cancer," Frontiers in Oncology, vol. 3, article 153, 2013.

[93] D. Mezzanzanica, M. Bagnoli, L. de Cecco, B. Valeri, and S. Canevari, "Role of microRNAs in ovarian cancer pathogenesis and potential clinical implications," International Journal of Biochemistry and Cell Biology, vol. 42, no. 8, pp. 1262-1272, 2010.

[94] M. V. Iorio, R. Visone, G. di Leva et al., "MicroRNA signatures in human ovarian cancer," Cancer Research, vol. 67, no. 18, pp. 8699-8707, 2007.

[95] E. J. Nam, H. Yoon, S. W. Kim et al., "MicroRNA expression profiles in serous ovarian carcinoma," Clinical Cancer Research, vol. 14, no. 9, pp. 2690-2695, 2008.

[96] L. Zhang, S. Volinia, T. Bonome et al., "Genomic and epigenetic alterations deregulate microRNA expression in human epithelial ovarian cancer," Proceedings of the National Academy of Sciences of the United States of America, vol. 105, no. 19, pp. 7004-7009, 2008.

[97] H. Yang, W. Kong, L. He et al., "MicroRNA expression profiling in human ovarian cancer: miR-214 induces cell survival and cisplatin resistance by targeting PTEN," Cancer Research, vol. 68, no. 2, pp. 425-433, 2008.

[98] R. Eitan, M. Kushnir, G. Lithwick-Yanai et al., "Tumor microRNA expression patterns associated with resistance to platinum based chemotherapy and survival in ovarian cancer patients," Gynecologic Oncology, vol. 114, no. 2, pp. 253-259, 2009.

[99] D. Yang, Y. Sun, L. Hu et al., "Integrated analyses identify a master microRNA regulatory network for the mesenchymal 
subtype in serous ovarian cancer," Cancer Cell, vol. 23, no. 2, pp. 186-199, 2013.

[100] N. Yang, S. Kaur, S. Volinia et al., "MicroRNA microarray identifies Let-7i as a novel biomarker and therapeutic target in human epithelial ovarian cancer," Cancer Research, vol. 68, no. 24, pp. 10307-10314, 2008.

[101] S. Kumar, A. Kumar, P. P. Shah, S. N. Rai, S. K. Panguluri, and S. S. Kakar, "MicroRNA signature of cis-platin resistant vs. cisplatin sensitive ovarian cancer cell lines," Journal of Ovarian Research, vol. 4, no. 1, article 17, 2011.

[102] S. W. Shahab, L. V. Matyunina, C. G. Hill et al., "The effects of MicroRNA transfections on global patterns of gene expression in ovarian cancer cells are functionally coordinated," $B M C$ Medical Genomics, vol. 5, article 33, 2012.

[103] F. Morani, R. Titone, L. Pagano et al., "Autophagy and thyroid carcinogenesis: genetic and epigenetic links," Endocrine-Related Cancer, vol. 21, no. 1, pp. R13-R29, 2013.

[104] S. Arico, A. Petiot, C. Bauvy et al., "The tumor suppressor PTEN positively regulates macroautophagy by inhibiting the phosphatidylinositol 3-kinase/protein kinase B pathway," The Journal of Biological Chemistry, vol. 276, no. 38, pp. 3524335246, 2001.

[105] Y. Tay, L. Kats, L. Salmena et al., "Coding-independent regulation of the tumor suppressor PTEN by competing endogenous mRNAs," Cell, vol. 147, no. 2, pp. 344-357, 2011.

[106] Y. Lou, X. Yang, F. Wang, Z. Cui, and Y. Huang, "MicroRNA21 promotes the cell proliferation, invasion and migration abilities in ovarian epithelial carcinomas through inhibiting the expression of PTEN protein," International Journal of Molecular Medicine, vol. 26, no. 6, pp. 819-827, 2010.

[107] R. C. Friedman, K. K.-H. Farh, C. B. Burge, and D. P. Bartel, "Most mammalian mRNAs are conserved targets of microRNAs," Genome Research, vol. 19, no. 1, pp. 92-105, 2009.

[108] B. John, A. J. Enright, A. Aravin, T. Tuschl, C. Sander, and D. S. Marks, "Human microRNA targets," PLoS Biology, vol. 2, no. 11, article e363, 2004.

[109] L. B. Frankel, J. Wen, M. Lees et al., "microRNA-101 is a potent inhibitor of autophagy," The EMBO Journal, vol. 30, no. 22, pp. 4628-4641, 2011.

[110] A. Semaan, A. M. Qazi, S. Seward et al., "MicroRNA-101 inhibits growth of epithelial ovarian cancer by relieving chromatinmediated transcriptional repression of p21waf1/cip1," Pharmaceutical Research, vol. 28, no. 12, pp. 3079-3090, 2011.

[111] M. Sonego, M. Schiappacassi, S. Lovisa et al., "Stathmin regulates mutant p53 stability and transcriptional activity in ovarian cancer," EMBO Molecular Medicine, vol. 5, no. 2, pp. 707-722, 2013.

[112] Z. Zhao, X.-F. Liu, H.-C. Wu et al., "Rab5a overexpression promoting ovarian cancer cell proliferation may be associated with APPL1-related epidermal growth factor signaling pathway," Cancer Science, vol. 101, no. 6, pp. 1454-1462, 2010.

[113] W. Jia, J. O. Eneh, S. Ratnaparkhe, M. K. Altman, and M. M. Murph, "MicroRNA-30c-2* expressed in ovarian cancer cells suppresses growth factor-induced cellular proliferation and downregulates the oncogene BCL9," Molecular Cancer Research, vol. 9, no. 12, pp. 1732-1745, 2011.

[114] H. Lee, C. S. Park, G. Deftereos et al., "MicroRNA expression in ovarian carcinoma and its correlation with clinicopathological features," World Journal of Surgical Oncology, vol. 10, article 174, 2012.
[115] S. Marchini, D. Cavalieri, R. Fruscio et al., "Association between miR-200c and the survival of patients with stage I epithelial ovarian cancer: a retrospective study of two independent tumour tissue collections," The Lancet Oncology, vol. 12, no. 3, pp. 273-285, 2011.

[116] K. Degenhardt, R. Mathew, B. Beaudoin et al., "Autophagy promotes tumor cell survival and restricts necrosis, inflammation, and tumorigenesis," Cancer Cell, vol. 10, no. 1, pp. 51-64, 2006.

[117] M. T. Rosenfeldt and K. M. Ryan, "The role of autophagy in tumour development and cancer therapy," Expert Reviews in Molecular Medicine, vol. 11, p. e36, 2009.

[118] D. Mezzanzanica, S. Canevari, L. D. Cecco, and M. Bagnoli, "miRNA control of apoptotic programs: focus on ovarian cancer," Expert Review of Molecular Diagnostics, vol. 11, no. 3, pp. 277-286, 2011. 


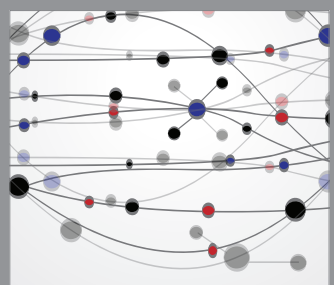

The Scientific World Journal
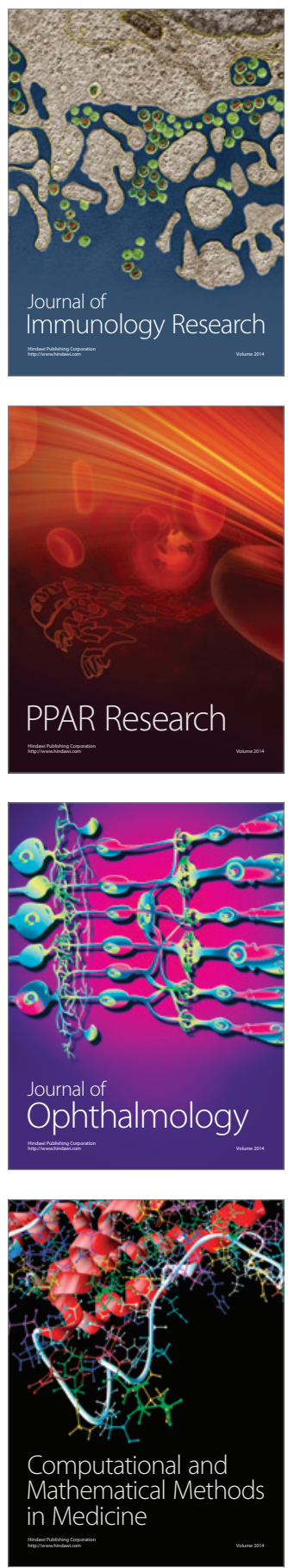

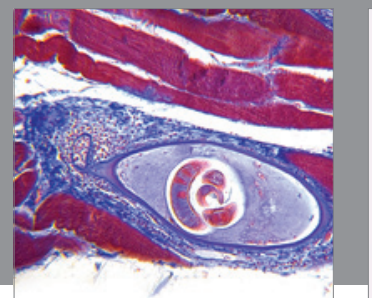

Gastroenterology

Research and Practice
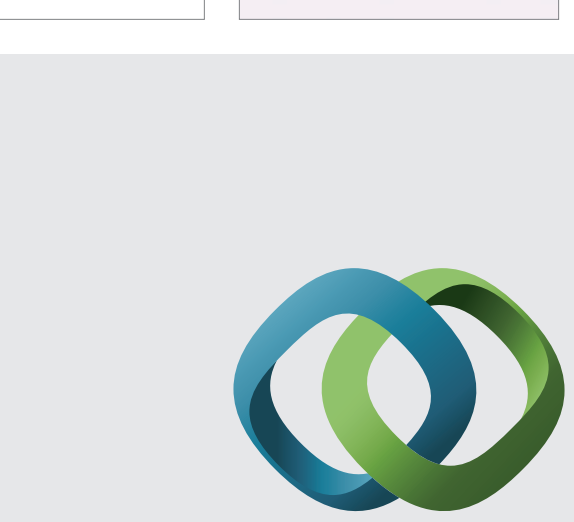

\section{Hindawi}

Submit your manuscripts at

http://www.hindawi.com
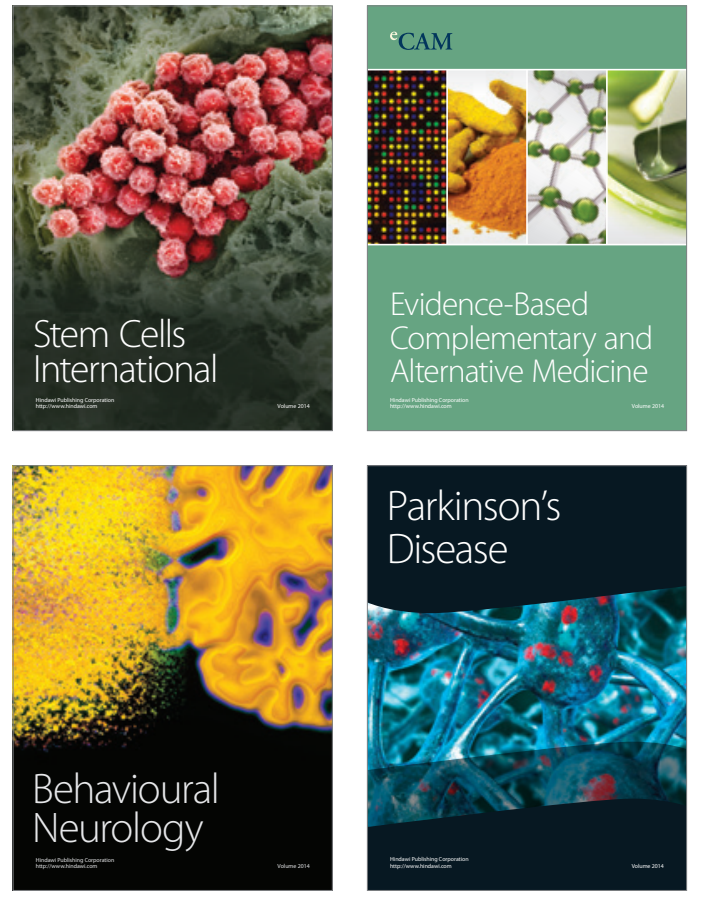
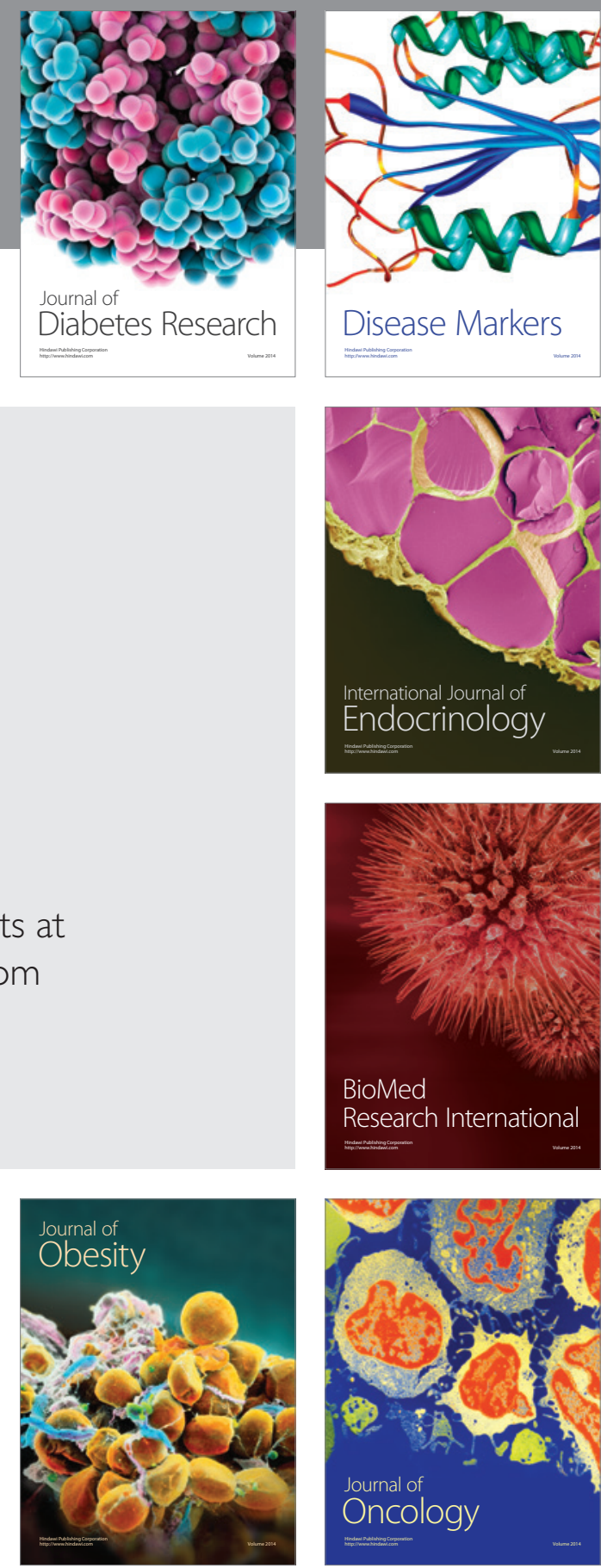

Disease Markers
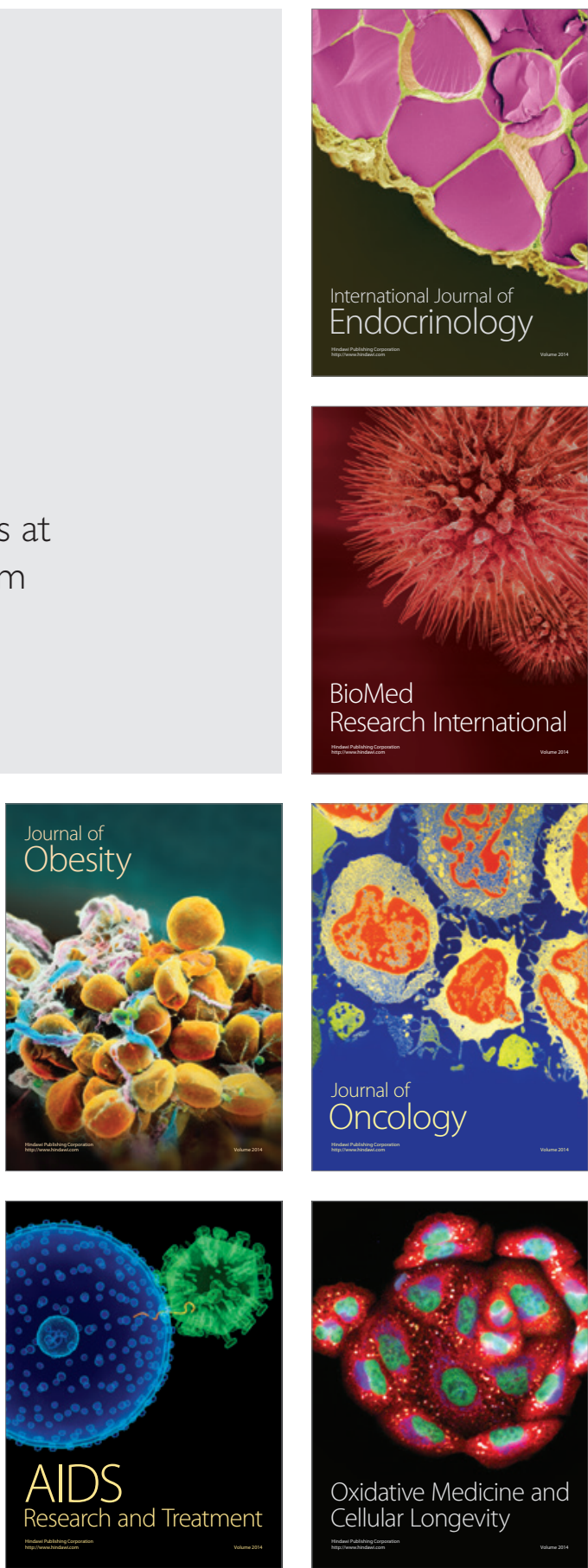